\title{
Tracking false-negative results in molecular diagnosis: proposal of a triplex-PCR based method for leishmaniasis diagnosis
}

\author{
Suênia da Cunha Gonçalves-de-Albuquerque, Rômulo Pessoa e Silva, Rayana Carla Silva de Morais, \\ Lays Adrianne Mendonça Trajano-Silva, Carlos Gustavo Régis-da-Silva, Sinval Pinto Brandão-Filho \\ and Milena de Paiva-Cavalcanti*
}

\begin{abstract}
Background: Molecular biological methods have become increasingly relevant to the diagnosis and control of infectious diseases, such as leishmaniasis. Since various factors may affect the sensitivity of PCR assays, including DNA yield and purity, an optimal extraction method is pivotal. Losses of a parasite's DNA during extraction may significantly impair its detection by PCR and lead to false-negative results. This study proposes a triplex PCR assay targeting the parasite's DNA, an external control (pUC18) and an internal control (G3PD) for accurate diagnosis of leishmaniasis.

Results: Two primer pairs were designed to detect the plasmid pUC18 and a triplex PCR assay targeting the Leishmania braziliensis kinetoplast DNA, the external control and the internal control was standardized. The triplex PCR assay was assessed for its ability to detect the three target DNA fragments simultaneously.

PCR products from pUC18 DNA resulted in bands of 368 (P1) and 316 (P2) base pairs (bp). The triplex PCR optimized with the chosen external control system (P1) allowed the simultaneous detection of the internal control (G3PD - $567 \mathrm{bp})$ as well as of small quantities (10 pg) of the target parasite's DNA, detected by amplification of a 138 bp product.

Conclusions: The new tool standardized herein enables a more reliable interpretation of PCR results, mainly by contributing to quality assurance of leishmaniasis diagnosis. Furthermore, after simple standardization steps, this protocol could be applied to the diagnosis of other infectious diseases in reference laboratories. This triplex PCR enables the assessment of small losses during the DNA extraction process, problems concerning DNA degradation (sample quality) and the detection of L. braziliensis kDNA.
\end{abstract}

Keywords: Extraction control, Multiplex PCR, pUC18, Leishmaniasis, Diagnosis, False-negative result

\section{Background}

Methods in molecular biology have become extremely relevant to the diagnosis and control of infectious diseases, such as leishmaniasis. Information on DNA sequences has been extensively exploited for the development of polymerase chain reaction (PCR) based assays for various applications, including understanding of parasite genetics and diagnosis of parasitic diseases [1]. DNA analysis offers

\footnotetext{
* Correspondence: mp@cpqam.fiocruz.br

Departamento de Imunologia, Centro de Pesquisas Aggeu Magalhães (CPqAM), Av. Prof. Moraes Rego, s/n, Recife, Pernambuco CEP 50670-420,
} Brasil

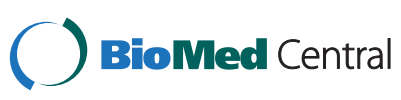

advantages over traditional serological and parasitological methods, including decreased sample processing time and elimination of the need for culturing [2,3]. As a result, medical and veterinary diagnostic tools and public health laboratories worldwide are increasingly being called upon to introduce molecular diagnostic tests for both endemic and exotic diseases [4].

PCR and its variations (e.g., nested, multiplex, real-time) have contributed to the detection of disease agents in humans and animals, including Leishmania spp. with high sensitivity and specificity [5-7]. Additionally, the possibility of combining multiple targets in the same assay enables 
the identification of parasites to the species level, the evaluation of sample integrity and also PCR performance on pools of phlebotomine sandflies [8-12].

Recently, a duplex PCR assay was standardized to evaluate the integrity of the DNA template by amplifying the glyceraldehyde-3-phosphate dehydrogenase gene (G3PD or GAPDH) of mammals in the same reaction for the diagnosis of Leishmania spp. infection [7]. The quality of the DNA samples extracted from blood and biopsies was evaluated by including a primer system to detect the G3PD gene in two standardized PCR assays for L. infantum (mVL) or L. braziliensis (mACL). The expression of this gene in all mammalian cells ensures its detection in samples whose conditions are suitable for diagnostic tests [13-15]. In the aforementioned study, the endogenous control was negative in $33 \%$ of the samples tested, demonstrating losses of reliability due to poor sample quality. In addition, some known positive samples, with quality assured by the G3PD detection, were PCR-negative for the main DNA target (L. infantum). These results indicated the necessity of not only ensuring the high quality of each individual sample, but also assessing possible losses of minimal amounts of the target parasite's DNA.

The extraction of nucleic acids from biological samples is a critical step and may result in losses of the target DNA [16]. Since various factors may affect the sensitivity of PCR assays, including DNA yield and purity, an optimal extraction method is essential. In recent years, commercial extraction kits have become available for blood and other biological specimens, such as skin. These kits perform direct cell lysis, speeding up sample processing and reducing the potential of variability, which has led to common use. However, extraction protocols often suffer from inadequacies including incomplete cell lysis, DNA binding to surfaces, poor DNA recovery and the co-extraction of salts and proteins that inhibit DNA-DNA hybridization and enzymatic reactions [16,17].

Realizing the importance of DNA extraction for the proper functioning of PCR-based methods, several groups have evaluated the efficiency of commercial kits for different types of samples [16,18-20]. Nevertheless, the most common PCR protocols monitor the sample quality by spectrophotometric determination of DNA or in separate reactions, neither controlling for PCR inhibition nor confirming successful DNA extraction recovery, ultimately increasing the costs and chances of false-negative results. Conversely, the detection of a known-to-be-present DNA sequence in the sample may reveal possible losses of genetic material during the purification process, thus enabling a more correct interpretation of the PCR results. Therefore, to refine the molecular diagnosis of human and canine leishmaniasis, this study assessed a molecular triplex PCR assay by targeting an external control (a commercial plasmid), an internal control (a housekeeping gene) and the target parasite's DNA (L. braziliensis kinetoplast DNA).

Compared to the traditional PCR protocols, the protocol presented herein allows a better interpretation of PCR results and promote quality assurance of the leishmaniasis diagnosis. The cost-benefit ratio is improved by ensuring the quality of results sample-by-sample, along with the simultaneous detection of Leishmania spp. Performing three PCRs in one mixing saves reagents, which makes it a rational decision for repeating reactions. Additionally, this method may be adapted for the molecular diagnosis of any infectious disease, providing fast results with a small margin of error.

\section{Methods}

\section{Blood samples and controls}

Human and canine blood samples were collected from one healthy person and two healthy dogs and used as controls. These samples were used to produce known negative and positive controls for the optimization tests. Informed consent was obtained from the dogs' owners and the person included in the study, and all procedures were approved by the Research Ethics Committee (CEPFIOCRUZ/PE, 42/2010) and by the Ethics Committee for Animal Use (CEUA- FIOCRUZ/RJ, LW-41/10 and LW-1/11) of our institution. As positive controls, a blood sample from a healthy dog and one from the human were spiked with genomic DNA of L. braziliensis (MHOM/BR/ 1975/M2903): $\sim 4.5 \times 10^{3}$ parasites/mL were used, considering the detection limit $(\mathrm{mACL}=10 \mathrm{pg})$ of the duplex PCR as determined previously [7].

\section{DNA extraction by commercial kit}

Blood DNA extraction was performed using a commercial kit (illustra ${ }^{\oplus}$ blood genomicPrep Mini Spin Kit, GE Healthcare, USA), following the manufacturer's instructions and comprising five basic steps: blood cell lysis, load and bind, wash 1, wash 2, and elution. After protein degradation and cell lysis, before the second step (load and bind), the plasmid pUC18 was added according to the predetermined limit of detection.

\section{Plasmid pUC 18, primers design and multiplex PCR standardization}

The commercial plasmid pUC18 (Boehringer Mannheim, Brazil) was used to assess DNA losses during the extraction process. Two primer pairs (P1-P1f: 5' -GTAATAGCG AAGAGGCC-3'; P1r: 5' -TAAGAAACCATTATTATC-3' and P2-P2f: 5'-TTGTACTGAGAGTGCAC-3'; P2r: 5'CAGGAAACAGCTATGAC-3') were designed based on two sequences available in GenBank [GenBank: L08752] and [Genbank:L09136]. PCR trials were conducted to evaluate the performance of the two pUC18 detection 
systems. Non-template control (NTC) and three different concentrations of pUC18 were included in each PCR run. Based on these preliminary results, the primer pair with the best performance was chosen to compose the triplex system. The detection limit of the PCR was assessed by testing ten-fold serial dilutions (from $50 \mathrm{ng} / \mu \mathrm{L}$ to $0.5 \mathrm{fg} / \mu \mathrm{L}$ ) of pUC18. Concentrations between 1 and $20 \mu \mathrm{M}$ of the forward $(\mathrm{P} f)$ and reverse $(\mathrm{Pr})$ primers were tested to determine the optimal amount of primers to be included in the duplex PCR reactions for the diagnosis of cutaneous leishmaniasis (mACL) [7].

For the first triplex PCR trials, according to the preliminary results, the plasmid pUC18 was added to negative and positive controls whereas each primer $(\mathrm{P} f$ and $\mathrm{P} r$ ) was added to the mACL master mix, containing the primers previously designed [7] for internal control detection (G1f: 5'-ATCTTCCAGGAGCGAGATCCC-3'; G2r: 5'-CTGC TTCACCACCTTCTTGAT-3'). The primers kDNAf (5'-ATGCCTCTGGGTAGGGGCGTTC-3') and kDNA $r$ (5'-GGGAGCGCGGCCCACTATATT-3'), designated as kDNA1 system, were designed by our research group to detect the conserved region of the L. braziliensis kDNA. The standardization process was performed by analyzing the results of the interactions among the systems $\mathrm{P} f / \mathrm{Pr}$, G3PD (endogenous control), and kDNA1. When necessary, changes were made in the cycling conditions by testing different annealing and extension temperatures performed in the Eppendorf Mastercycler gradient (Eppendorf AG, Germany). To assess the best conditions for the triplex PCR, different amounts of each reagent ( $\mathrm{dNTP}, \mathrm{MgCl}_{2}$ and recombinant Taq DNA Polymerase, Invitrogen, Brazil) were also evaluated.

\section{Specificity of primer pairs on triplex assays}

To evaluate the specificity of the primers in a triplex PCR format, a sample containing the three targets $(L$. braziliensis, G3PD gene, and pUC18) was subjected to PCR amplification by the three primer sets (kDNA1, G3PD and P1) separately, under standardized conditions. The PCR products obtained by this experiment were purified and sequenced using an automatic sequencer (ABI Prism 3100 Genetic Analyzer, Applied Biosystems, USA). The obtained sequences were analyzed using BioEdit software (http://www.mbio.ncsu.edu/bioedit/bioedit.html) and compared with similar nucleotide sequences available in GenBank using the Basic Local Alignment Search Tool (BLASTn) (http://blast.ncbi.nlm.nih.gov).

\section{Gel electrophoresis and documentation}

Amplicons were resolved in 1.5\% agarose gel electrophoresis, stained with ethidium bromide $(10 \mathrm{mg} / \mathrm{mL})$. A $100 \mathrm{bp}$ Ladder DNA (GibcoBRL Life Technologies, USA) was used as the molecular marker. Gel pictures were taken using a Kodak MI GL100 Imaging System.

\section{Results}

The sequences of the two primer pairs targeting the plasmid pUC18 were: P1 $f$ (5'-CGTAATAGCGAAGAGGCC$\left.3^{\prime}\right)$ and P1r (5'-TAAGAAACCATTATTATC-3') for the system P1; and P2f (5'-TTGTACTGAGAGTGCAC-3') and P2 $r$ (5'-CAGGAAACAGCTATGAC-3') for the system P2. Amplicons from pUC18 DNA resulted in bands of 368 (P1) and 316 (P2) base pairs (bp), being suitable for multiplex PCR with G3PD (567 bp) and kDNA1 (138 bp). Based on its excellent performance (Figure $1-\mathrm{A}$ ), the system P1

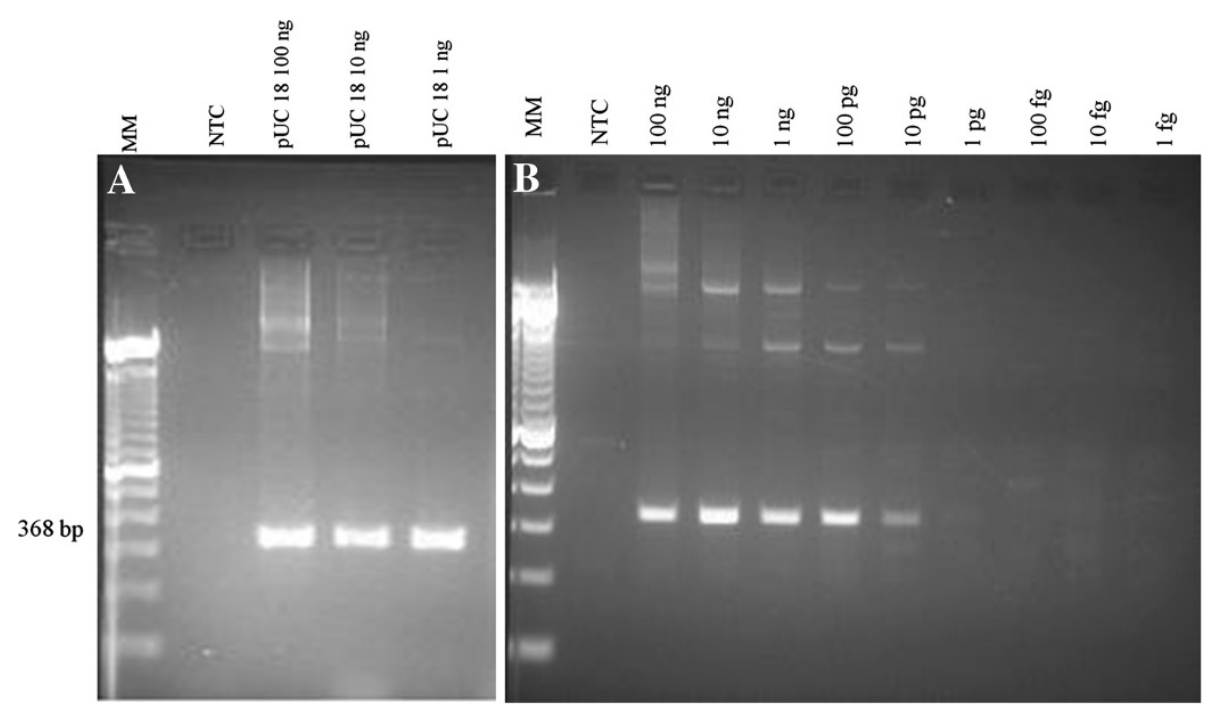

Figure 1 Preliminary test of $\mathbf{P} 1$ primer set and detection limit determination. (A) Preliminary test of primers P1f/P1r using different concentrations of pUC18. Note that spurious bands formed by whole plasmid electrophoresis runs can occur when using high concentrations of pUC18 in the reaction. (B) Sensitivity of system P1 (uniplex PCR) determined by ten-fold serial dilution (in nanograms per microliter) of pure pUC18 DNA. NTC - no template control. MM: molecular marker, 100 bp Ladder DNA (GibcoBRL Life Technologies, USA). 
was chosen to compose the triplex PCR. The system P2 was not reproducible. The uniplex PCR carried out with pure pUC18 DNA was able to detect a concentration as low as $5 \mathrm{pg} / \mu \mathrm{L}$ (total of $10 \mathrm{pg}$ per reaction mixture) as shown in Figure $1-B$. The lowest amount of primers that held this sensitivity (10 $\mu \mathrm{M}$ of each of them) was chosen to compose the first triplex PCR trials.

The observation of competition among primer pairs and target templates indicated a necessity to modify some conditions of $\mathrm{mACL}$ and P1 standardized initially. Simultaneous amplification of 10 pg per reaction pUC18, G3PD, and L. braziliensis was obtained under the following conditions: Taq Polymerase Buffer $(0.7 \mu \mathrm{M}$ Tris- $\mathrm{HCl}$, $1.8 \mathrm{nM} \mathrm{KCl}, \mathrm{pH} 8.4), 5.6 \mathrm{nM} \mathrm{MgCl}_{2}, 40 \mathrm{nM}$ dNTPs, $2 \mu \mathrm{M}$ of each primer kDNAf/kDNA $r 1,5 \mu \mathrm{M}$ of each primer G1F/G2R, $20 \mu \mathrm{M}$ of each primer $\mathrm{P} f / \mathrm{P} r, 10 \mathrm{U}$ of Taq polymerase and $2 \mu \mathrm{L}$ of DNA template.

Sequences of amplicons generated with the system P1 showed high homology (100\% identity) with pUC18 cloning vector [GenBank: L08752.1]. High homologies (100\% identity) were also found with other cloning vectors [GenBank: JX069764.1, JQ927446.1, HQ207194.1, and FJ389180.1] and with Bacillus subtilis [GenBank: CP002468.1]. As to G3PD, the highest homology (75\%) was found with a sequence of a human $x$-linked GAPD pseudogene [GenBank: X01111.1]. The kDNA1 product presented $94 \%$ similarity to a sequence of L. braziliensis strain MHOM/BR/75/M2904 [GenBank: FR799010.1]. Identities between $88 \%$ and $93 \%$ were also found with other species of the subgenus Viannia (L. peruviana, L. guyanensis, and L. panamensis) (data not shown).

\section{Discussion}

The purpose of this work was to suggest a method to track possible causes of false-negative results in microbiological diagnosis by PCR, requiring minimal technical training. The triplex PCR assay proposed herein provides a rapid molecular tool to assess the occurrence of falsenegative results by detecting simultaneously two quality controls and the target parasite's DNA simultaneously.

In theory, the differences in the guanine and cytosine (GC) contents of primers used (e.g., P1 and kDNA1) could interfere in the annealing temperatures for each primer pair and eventually affect the triplex PCR performance. However, no interference was observed under the standardized conditions.

A lack of reproducibility of the P1 in detecting the extraction control was observed only in positive samples. Depending on the parasitic load in the positive specimens, the early amplification of the parasite's DNA consumes the reagents, leading to no amplification of the DNA reporter. Indeed, the P1 system gave reproducible results during the optimization process in L. braziliensis-negative samples, being helpful in diagnosis interpretation and thus achieving the proposed aim. Even minimal losses of genetic material may affect significantly the detection of the parasite's DNA, which is often found in small quantities, leading to incorrect diagnostic conclusions. As a recognized limitation, high molecular weight bands could be observed in agarosis gels, representing excess and/or folding of pUC 18 plasmid in the samples. However, the appearance of these bands does not confuse the interpretation of the results, as the amplicon size of each system is well known and was demonstrated by sequence analysis to be specific.

Against this background, this new tool provides a more reliable interpretation of the PCR results, as shown in Table 1, especially by virtue of contributing to quality assurance of leishmaniasis diagnosis. Furthermore, after simple standardization steps, this protocol could be applied to the diagnosis of other infectious diseases in reference laboratories.

While competition between targets was recorded initially, changes in the PCR conditions allowed us to eliminate competition problems, even while maintaining the detection limit (18 parasites per reaction), previously obtained with the mACL duplex system [7]. The simultaneous amplification of three different targets may interfere in the detection limit of PCR as compared with simplex PCR protocols, which may be able to detect minimal amounts of the parasite's DNA [21]. The main advantage of the triplex assay presented herein is the amplification of three different targets to ensure the quality of the result. The analysis of DNA sequences showed no cross-amplification among the three primer pairs included in the triplex PCR assay. Primers designed to detect the plasmid pUC18 and the housekeeping gene G3PD did not amplify Leishmania spp. DNA, thereby reducing the possibilities of false-positive results to zero. Interestingly, BLASTn searches revealed that the pUC18 sequence was similar to sequences of other plasmids, which are based on the pUC18 sequence and could also be tested and optimized, according to the availability in each laboratory or research group.

The continuous refinement of PCR technologies (e.g., introduction of robotics) and the increasing demand for rapid and efficient diagnostic tools are leading to an overall reduction of costs, making PCR-based methods more accessible $[22,23]$. As occurs with other diagnostic methods (e.g., serology), PCR-based methods are also liable to false-positive (e.g., due to background DNA contamination) and false-negative results. False-negative results may be attributable to many factors, including low amount of template DNA in the test sample, inadequate removal of PCR inhibitors, ineffective release of microbial DNA content from the host cells, and poor DNA recovery after extraction and purification steps. As a possible solution to clarify the presence of inhibitors or degraded target DNA 
Table 1 Interpretation and actions suggested after observation of different positivity combinations of the quality controls and Leishmania spp. main target in the triplex PCR reaction

\begin{tabular}{|c|c|c|}
\hline $\begin{array}{l}\text { Result/PCR target } \\
\text { positivity }\end{array}$ & Interpretation/meaning & Action \\
\hline G3PD 567 bp (+) & \multirow[t]{3}{*}{ Valid results for parasite diagnosis } & \multirow[t]{3}{*}{ Conclude diagnostic test observation } \\
\hline pUC 316 bp (+) & & \\
\hline L. braziliensis $138 \mathrm{bp}(+)$ & & \\
\hline G3PD 567 bp (+) & \multirow[t]{3}{*}{ Valid results for parasite diagnosis despite small loss of DNA in extraction } & \multirow[t]{3}{*}{ Conclude diagnostic test observation } \\
\hline pUC 316 bp (-) & & \\
\hline L. braziliensis $138 \mathrm{bp}(+)$ & & \\
\hline G3PD 567 bp (-) & \multirow[t]{3}{*}{ Valid results for parasite diagnosis despite small degradation of sample } & \multirow[t]{3}{*}{ Conclude diagnostic test observation } \\
\hline pUC 316 bp (+) & & \\
\hline L. braziliensis $138 \mathrm{bp}(+)$ & & \\
\hline G3PD 567 bp (-) & \multirow{3}{*}{$\begin{array}{l}\text { Degradation of DNA sample/presence of PCR inhibitors and/or whole } \\
\text { DNA loss during extraction }\end{array}$} & \multirow{3}{*}{$\begin{array}{l}\text { Repeat diagnostic procedure since the blood } \\
\text { sample collection }\end{array}$} \\
\hline pUC 316 bp (-) & & \\
\hline L. braziliensis 138 bp (-) & & \\
\hline G3PD 567 bp (-) & \multirow[t]{3}{*}{ Degradation of DNA sample before extraction } & \multirow{3}{*}{$\begin{array}{l}\text { Repeat diagnostic procedure since the blooc } \\
\text { sample collection }\end{array}$} \\
\hline pUC 316 bp (+) & & \\
\hline L. braziliensis $138 \mathrm{bp}(-)$ & & \\
\hline G3PD 567 bp (+) & \multirow{3}{*}{$\begin{array}{l}\text { Significant DNA loss (affecting mainly parasite genome) during } \\
\text { extraction process }\end{array}$} & \multirow[t]{3}{*}{ Repeat the DNA extraction procedure } \\
\hline pUC 316 bp (-) & & \\
\hline L. braziliensis 138 bp (-) & & \\
\hline G3PD 567 bp (+) & \multirow{3}{*}{$\begin{array}{l}\text { True negative result for Leishmania detection assured by the positivity of } \\
\text { quality controls }\end{array}$} & \multirow[t]{3}{*}{ Conclude diagnostic test observation } \\
\hline pUC 316 bp (+) & & \\
\hline L. braziliensis 138 bp (-) & & \\
\hline
\end{tabular}

in samples, constitutive genes have been used in parallel assays to assess the integrity of the DNA template $[7,15]$. To improve the cost-benefit ratio and to shorten the time consumed by this evaluation, we recently proposed a duplex PCR assay capable of detecting a housekeeping gene as an endogenous control [7]. Nevertheless, samples from patients with low parasite burden may contain minimal amounts of a parasite's DNA, which may be even more profoundly affected by degradation or losses during the pre-PCR stages. This fact suggests the need to include additional internal controls to monitor possible failures during critical steps, such as DNA purification. The addition of a reporter DNA template may indicate the presence of Taq DNA polymerase inhibitors and degraded microbial DNA, as well as losses of small DNA amounts during the extraction and purification processes.

The advantages of using internal or external controls have been demonstrated with various types of clinical samples [24-28]. For instance, an external DNA recovery standard has been developed for the determination of DNA recovery efficiency in soil samples tested by quantitative PCR [16].

In addition, the fact that the L. braziliensis kDNA amplicon presented homology in relation to kDNA regions of other Viannia species suggests that the primers and protocols reported in the study may be used directly or adapted for the detection of several species of these parasites.

\section{Conclusions}

The triplex PCR proposed herein enables the assessment of small losses during the DNA extraction process, problems concerning DNA degradation (sample quality) and the detection of L. braziliensis kDNA. To the best of our knowledge, no similar method has been applied to the molecular diagnosis of parasitic diseases using blood samples. An interesting insight of our group is the comparative analysis of the single PCR to the new triplex PCR protocol to maintain high diagnosis accuracy. This method may be applied to the molecular diagnosis of any infectious disease, providing quicker results with minimal margin of error.

\section{Ethics committee approval}

The present study was approved by the Ethics Committee for Animal Use (CEUA- FIOCRUZ/RJ, LW-41/10 and LW-1/11) of Oswaldo Cruz Foundation. 


\section{Consent}

Informed consent was obtained from the dogs' owners and the person included in the study. Moreover, all procedures were approved by the Research Ethics Committee of Oswaldo Cruz Foundation (CEP-FIOCRUZ/PE, 42/2010).

\section{Competing interests}

The authors declare that they have no competing interests.

\section{Authors' contributions}

MPC is the lead researcher of this study. MPC, SCGA and RPS designed the study. MPC and CGRS designed primers and gave intellectual support for this work. RPS, RCSM, LAMTS and SCGA performed experiments and their analysis. SCGA carried out the molecular genetic studies, analyzed amplicon sequencing and drafted the manuscript. SPBF and all authors read and approved the final version of this manuscript.

\section{Acknowledgments}

Thanks to the Program of Technological Development in Health Supplies (PDTIS/Fiocruz) for allowing us to use its facilities, and to the State of Pernambuco Research Foundation (FACEPE), the National Council for Scientific and Technological Development (CNPq)/PAPES VI and Coordination for the Improvement of Higher Education Personnel (CAPES) for financial support.

Received: 17 October 2013 Accepted: 7 April 2014 Published: 22 April 2014

\section{References}

1. Schallig HDFH, Oskam L: Molecular biological applications in the diagnosis and control of leishmaniasis and parasite identification. Trop Med Int Health 2002, 7(8):641-651.

2. Ogram AV, Sayler GS: The use of gene probes in the rapid analysis of natural microbial communities. J Ind Microbiol 1988, 3(5):281-292.

3. Tsai $\mathrm{YL}$, Olson BH: Rapid method for direct extraction of DNA from soil and sediments. Appl Environ Microbiol 1991, 57(4):1070-1074.

4. Frank E: Funding the public health response to terrorism. BMJ 2005, 331:378-379.

5. Akhavan AA, Mirhendi $H$, Khamesipour A, Alimohammadian MH, Rassi Y, Bates P, Kamhawi S, Valenzuela JG, Arandian MH, Abdoli H, Jalali-zand N, Jafari R, Shareghi N, Ghanei M, Yaghoobi-Ershadi MR: Leishmania species: detection and identification by nested PCR assay from skin samples of rodent reservoirs. Exp Parasitol 2010, 126(4):552-556.

6. Paiva-Cavalcanti M, Régis-da-Silva CG, Gomes YM: Comparison of real-time PCR and conventional PCR for detection of Leishmania (Leishmania) infantum infection: a mini-review. J Venom Anim Toxins Ind Trop Dis 2010, 16(4):537-542 [http://www.scielo.br/scielo.php?pid=S16789199201000040 0004\&script=sci_abstract]

7. Gonçalves SC, Régis-da-Silva CG, Brito MEFC, Brandão-Filho SP, PaivaCavalcanti M: Application of the mammalian glyceraldehyde-3-phosphate dehydrogenase gene for sample quality control in multiplex PCR for diagnosis of leishmaniasis. J Venom Anim Toxins Ind Trop Dis 2012, 8(2):188-197 [http://www.scielo.br/scielo.php?script=sci_arttext\&pid=S167891992012000200009]

8. Harris E, Kropp G, Belli A, Rodriguez B, Agabian N: Single-Step multiplex PCR assay for characterization of new world Leishmania complexes. J Clin Microbiol 1998, 36(7):1989-1995.

9. Jorquera A, González R, Marchán-Marcano E, Oviedo M, Matos M: MultiplexPCR for detection of natural Leishmania infection in Lutzomyia spp. captured in an endemic region for cutaneous leishmaniasis in state of Sucre, Venezuela. Mem Inst Oswaldo Cruz 2005, 100(1):45-48.

10. Rodríguez-González I, Marín C, Longoni SS, Mateo H, Alunda JM, Minaya G, Gutiérrez-Sánchez R, Vargas F, Sánchez-Moreno M: Identification of New World Leishmania species from Peru by biochemical techniques and multiplex PCR assay. FEMS Microbiol Lett 2007, 267(1):9-16.

11. de Pita-Pereira D, Cardoso MA, Alves CR, Brazil RP, Britto C: Detection of natural infection in Lutzomyia cruzi and Lutzomyia forattinii (Diptera: Psychodidae: Phlebotominae) by Leishmania infantum chagasi in an endemic area of visceral leishmaniasis in Brazil using a PCR multiplex assay. Acta Trop 2008, 107(1):66-69.
12. Oliveira DM, Reinhold-Castro KR, Bernal MV, Legriffon CM, Lonardoni MV, Teodoro U, Silveira TG: Natural infection of Nyssomyia neivai by Leishmania (Viannia) spp. in the state of Paraná, southern Brazil, detected by multiplex polymerase chain reaction. Vector Borne Zoonotic Dis 2011, 11(2):137-143.

13. Gilsbach R, Kouta M, Bönisch $H$, Brüss M: Comparison of in vitro and in vivo reference genes for internal standardization of real-time PCR data. Biotechniques 2006, 40(2):173-177.

14. Solano-Gallego L, Rodriguez-Cortes A, Trotta M, Zampieron C, Razia L, Furlanello T, Caldin M, Roura X, Alberola J: Detection of Leishmania infantum DNA by fret-based real-time PCR in urine from dogs with natural clinical leishmaniosis. Vet Parasitol 2007, 147(3-4):315-319.

15. Castilho TM, Camargo LM, MCMahon-Pratt D, Shaw JJ, Floeter-Winter LM: A real-time polymerase chain reaction assay for the identification and quantification of American Leishmania species on the basis of glucose-6phosphate dehydrogenase. Am J Trop Med Hyg 2008, 78(1):122-132.

16. Mumy KL, Findlay RH: Convenient determination of DNA extraction efficiency using an external DNA recovery standard and quantitativecompetitive PCR. J Microbiol Methods 2004, 57(2):259-268.

17. Alm EW, Zheng D, Raskin L: The presence of humic substances and DNA in RNA extracts affects hybridization results. App/ Environ Microbiol 2000, 66(10):4547-4554.

18. Coyne SR, Craw PD, Norwood DA, Ulrich MP: Comparative analysis of the Schleicher and Schuell IsoCode Stix DNA isolation device and the Qiagen QIAamp DNA mini Kit. J Clin Microbio/ 2004, 42(10):4859-4862.

19. Whitehouse CA, Hottel HE: Comparison of five commercial DNA extraction kits for the recovery of Francisella tularensis DNA from spiked soil samples. Mol Cell Probes 2007, 21(2):92-96.

20. Dauphin LA, Walker RE, Petersen JM, Bowen MD: Comparative evaluation of automated and manual commercial DNA extraction methods for detection of Francisella tularensis DNA from suspensions and spiked swabs by real-time polymerase chain reaction. Diagn Microbiol Inf Dis 2011, 70(3):299-306.

21. Schönian G, Nasereddin A, Dinse N, Schweynoch C, Schallig HD, Presber W, Jaffe CL: PCR diagnosis and characterization of Leishmania in local and imported clinical samples. Diagn Microbiol Infect Dis 2003, 47(1):349-358.

22. Livengood CH 3rd, Wrenn JW: Evaluation of COBAS AMPLICOR (Roche): accuracy in detection of Chlamydia trachomatis and Neisseria gonorrhoeae by coamplification of endocervical specimens. J Clin Microbiol 2001, 39(8):2928-2932.

23. Yang S, Rothman RE: PCR-based diagnostics for infectious diseases: uses, limitations, and future applications in acute-care settings. Lancet Infect Dis 2004, 4(6):337-348.

24. Reiss RA, Rutz B: Quality control PCR: a method for detecting inhibitors of Taq DNA polymerase. Biotechniques 1999, 27(5):920-926.

25. Cubero J, van der Wolf J, van Beckhoven J, López MM: An internal control for the diagnosis of crown gall by PCR. J Microbiol Methods 2002, 51(3):387-392.

26. Lund M, Madsen M: Strategies for the inclusion of an internal amplification control in conventional and real time PCR detection of Campylobacter spp. in chicken fecal samples. Mol Cell Probes 2006, 20(2):92-99.

27. Murphy NM, McLauchlin J, Ohai C, Grant KA: Construction and evaluation of a microbiological positive process internal control for PCR-based examination of food samples for Listeria monocytogenes and Salmonella enterica. Int J Food Microbiol 2007, 120(1-2):110-119.

28. Leblanc-Maridor M, Garénaux A, Beaudeau F, Chidaine B, Seegers H, Denis M, Belloc C: Quantification of Campylobacter spp. in pig feces by direct real-time PCR with an internal control of extraction and amplification. J Microbiol Methods 2011, 85(1):53-61.

doi:10.1186/1678-9199-20-16

Cite this article as: Gonçalves-de-Albuquerque et al.: Tracking

false-negative results in molecular diagnosis: proposal of a triplex-PCR based method for leishmaniasis diagnosis. Journal of Venomous Animals and Toxins including Tropical Diseases 2014 20:16. 